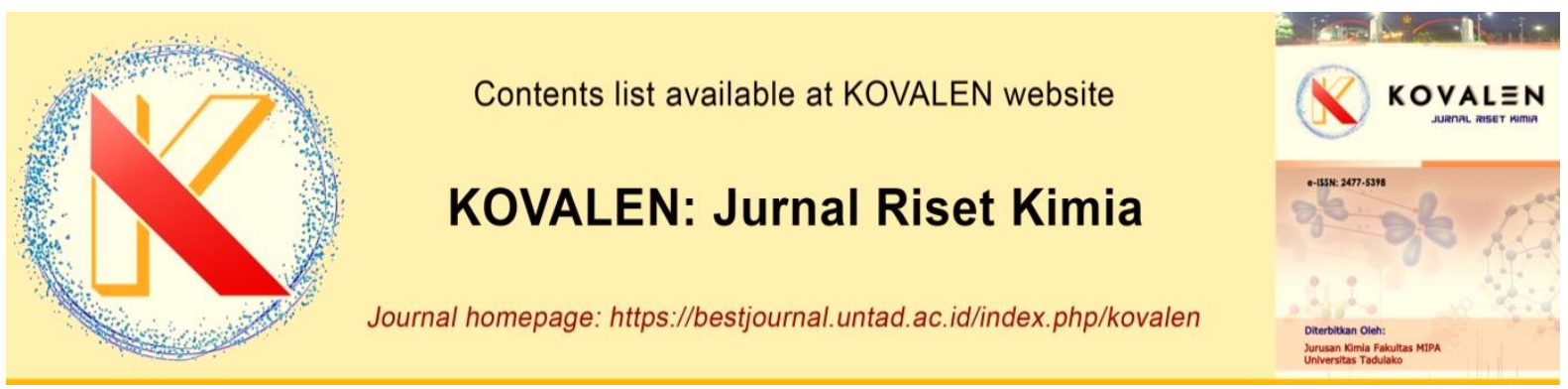

\title{
Pengaruh Konsentrasi Surfaktan Non-Ionik Terhadap Viskositas Perekat Polivinil Asetat Berbasis Air
}

\section{[Effect of Non-Ionic Surfactant on Water-Based Adhesive Viscosity]}

\author{
Rony Pasonang Sihombing*, Robby Sudarman, Agustinus Ngatin \\ Department of Chemical Engineering, Politeknik Negeri Bandung \\ *Corresponding author: rony.pasonang.sihombing@polban.ac.id
}

\begin{abstract}
Substrate combining could be done by using adhesive. In Indonesia, especially industrial field, solvent base adhesives were still being developed. This kind of adhesive was not environmental friendly and not safe handling. Therefore, Polyvinyl Acetate (PVAc) water-based adhesive was prepared as an outcome of this research as one of solution to overcome the problem above. Effect of surfactant concentration on the viscosity was aimed at this research. Semi continuous polymerization with stirring motor rates on $50-500 \mathrm{rpm}$ was used (optional). Pressure of $1 \mathrm{~atm}, 75^{\circ} \mathrm{C}$ temperature, $5-6$ hours reaction time for each was used as polymerization operation in this research. Vinyl Acetate Monomer (VAM), partial hydrolysis Polyvinyl Alcohol (PVOH), water, Ammonium Persulfate (APS) were prepared as raw material. NP-10 and NP-06 were non-ionic surfactants which each concentration was varied in this research. Water-based adhesive with NP-06 concentration variation resulting in viscosity from $98 \mathrm{~m} . \mathrm{Pa}$ for $0.17 \%$ wt concentration to $213 \mathrm{~m} . \mathrm{Pa}$ for $0.68 \%$ wt concentration. While NP-10 concentration variation resulting viscosity from $143 \mathrm{~m} . \mathrm{Pa}$ for $0.17 \%$ wt to $321 \mathrm{~m}$.Pa for $0.68 \%$ wt concentration. Therefore, adhesive with NP-10 surfactant concentration variable has a higher viscosity rate than NP-06 ones.
\end{abstract}

Keywords: Water-based adhesive, non-ionic surfactant, adhesive viscosity

ABSTRAK. Penyatuan substrat dapat dilakukan dengan menggunakan perekat. Di Indonesia, khususnya di dunia industri, perekat berbasis pelarut organik masih banyak dikembangkan. Perekat jenis ini tidak aman bagi lingkungan dan juga kesehatan. Oleh karenanya, perekat Polivinil Asetat (PVAc) berbasis air dibuat sebagai luaran penelitian sebagai salah satu solusi mengatasi masalah diatas. Efek konsentrasi surfaktan terhadap viskositas dijadikan tujuan penelitian ini. Proses yang digunakan adalah polimerisasi semi kontinyu dengan pengadukan 50 - $500 \mathrm{rpm}$ (opsional). Kondisi operasi yang digunakan antara lain tekanan $1 \mathrm{~atm}$, suhu $75^{\circ} \mathrm{C}$, waktu sintesis 5 - 6 jam untuk tiap variabelnya. Vinil Asetat (VAM), Polivinil Alkohol (PVOH) jenis hidrolisis parsial, air, Ammonium Persulfat (APS) merupakan bahan baku yang dipakai dalam penelitian ini. Sedangkan NP-10 dan NP-06 merupakan surfaktan non-ionik yang konsentrasinya divariasikan dalam penelitian ini. Konsentrasi PVAc dibuat mulai $0 \%$ wt hingga $0.68 \%$ wt. Pada kondisi $0 \%$, viskositas PVAc yang dihasilkan $143 \mathrm{~m}$. Pa. Perekat berbasis air dengan variasi konsentrasi NP-06 memiliki hasil viskositas 98 m.Pa untuk konsentrasi $0.17 \%$ wt hingga $213 \mathrm{~m} . \mathrm{Pa}$ untuk konsentrasi $0.68 \% w t$. Sedangkan variasi konsentrasi NP-10 memiliki hasil viskositas $143 \mathrm{~m} . \mathrm{Pa}$ pada konsentrasi $0.17 \%$ wt hingga $321 \mathrm{~m} . P a$ pada konsentrasi $0.68 \% w t)$. Sehingga perekat dengan variabel konsentrasi surfaktan NP-10 memiliki variasi viskositas lebih tinggi daripada NP-06.

Kata kunci: Perekat berbasis air, surfaktan non-ionik, viskositas perekat

Riwayat artikel: Diterima 8 September 2020, Disetujui 22 Oktober 2020

Cara sitasi: Sihombing, R P., Sudarman, R., \& Ngatin, A. (2020). Pengaruh Konsentrasi Surfaktan Non-lonik Terhadap Viskositas Perekat Polivinil Asetat Berbasis Air. KOVALEN: Jurnal Riset Kimia, 6(3): 165-170.

DOI: https://doi.org/10.22487/kovalen.2020.v6.i3.15278 


\section{LATAR BELAKANG}

Di Indonesia, jenis perekat berbasis pelarut organik masih banyak ditemukan. Berdasarkan data statistik, ada peningkatan terkait dengan industri perekat di Indonesia (Kemenperin 2014). Fenomena adanya peningkatan terjadi pada jumlah pelaku industri perekat dimana pada tahun 2008 terdapat sekitar 40 unit dan berkembang hingga 49 unit pada tahun 2013. Hal ini berimplikasi pada jumlah tenaga kerja yang juga meningkat tiap tahunnya, dimana pada tahun 2008 terdapat sekitar 4000 orang dan bertambah rata-rata 5400 orang tiap tahunnya. Dengan demikian, penelitian terkait perekat ini dilakukan.

Perekat berbasis pelarut organik tidak aman bagi lingkungan dan juga kesehatan. Kandungan dari pelarut organik tersebut tergolong tidak ramah lingkungan dan menyebabkan berbagai macam penyakit apabila terhirup maupun tertelan. Penyakit yang mungkin terjadi yaitu leukemia, saluran pernapasan, bronchitis, kerusakan lever, atau gagal ginjal (Susilowati, 2011).

Oleh karenanya, penelitian perekat berbasis air dilakukan dengan pertimbangan ramah lingkungan dan lebih aman penanganannya. Dalam penelitian ini, perekat jenis polivinil asetat berbasis air dibuat untuk melihat bagaimana pengaruh surfaktan non ionik terhadap viskositasnya dengan menggunakan metode polimerisasi emulsi.

Polimerisasi emulsi terdiri dari air, monomer, emulsifier (surfaktan), dan inisiator, biasanya $30 \%$ monomer, $65 \%$ air dan sisanya surfaktan dan bahan aditif lainnya (Wang et al., 1994). Proses ini merupakan polimerisasi adisi radikal yang terjadi pada sistem heterogen. Hasil akhir yang diperoleh dari proses polimerisasi emulsi, yaitu cairan berwarna putih menyerupai susu yang umumnya disebut lateks ataupun dispersi koloid dalam media air. Ciri khas dari partikel-partikel tersebut adalah terdiri dari 1-10.000 makro molekul. Masing-masing makro molekul berisi sekitar 100-1.000.000 unit monomer. Proses polimerisasi pada polimerisasi emulsi berlangsung di dalam misel (Helmiyati et al., 2009). Semakin bertambah monomer yang digunakan dalam reaksi polimerisasi, maka monomer yang berpindah ke misel-misel pun semakin banyak, dan kemudian reaksinya berlanjut (Triwulandari, 2014).

PVAc adalah salah satu polimer aplikatif yang digunakan sebagai bahan perekat material. PVAc merupakan salah satu polimer yang dapat disintesis melalui proses yang disebut polimerisasi emulsi. Secara umum, polimerisasi emulsi PVAc adalah cairan putih susu mengandung 40-60\% polimer padat, sisanya adalah air, colloids protective, dan aditif lainnya (Berber et al., 2018).

PVAc termasuk jenis polimer termoplastis. Polimer termoplastis memiliki sifat fleksibel, yakni bila dipanaskan dapat melunak dan bila didinginkan dapat mengeras (kaku). PVAc biasa digunakan. Selain itu polimer ini juga bersifat sifat tahan suhu tinggi, memiliki daya regang tinggi serta larut dalam pelarut organik (Hong et al., 2018). Dalam pengaplikasiannya, polimer ini dapat digunakan sebagai bahan perekat material, cat, kertas, tekstil dan sebagainya. Reaksi PVAc ini berawal dari monomer VAM yang dipolimerisasi dengan menggunakan inisiator APS yang akan memberikan radikal bebas sehingga memecah ikatan rangkap pada struktur VAM menjadi PVAc.

PVAc berbasis air disintesis dengan polivinil alkohol yang dilarutkan terlebih dahulu 
dalam air sebagai proses awal untuk hidrolisis. Selanjutnya VAM ditambahkan dan diikuti komponen lain, salah satunya adalah surfaktan.

Surfaktan merupakan suatu zat yang mampu menurunkan tegangan antar muka dikarenakan strukturnya yang amphifilik, yaitu adanya dua gugus yang memiliki derajat polaritas yang berbeda pada satu molekul yang sama. Yang pertama adalah gugus hidrofilik, yang bersifat polar dan lainnya adalah gugus hidrofobik yang bersifat nonpolar (Hong et al., 2018). Surfaktan dapat digunakan sebagai chain transfer agent (CTA) dalam polimerisasi sehingga akan berpengaruh pada panjang rantai dan viskositas. Di samping itu dengan stabilisasi elektrostatisnya, surfaktan mampu menstabilkan polimer dalam sintetisnya dan dapat juga digunakan untuk menstabilkan pertumbuhan partikel selama proses polimerisasi (Shahidi, 2009). Dalam aplikasinya, penggunaan surfaktan dalam polimerisasi tidak melebihi $6 \mathrm{wt} \%$. Di industri, jenis surfaktan yang sering digunakan adalah anionik dan nonionik(Shahidi, 2009). Dalam penelitian ini, surfaktan jenis non-ionik digunakan karena berpengaruh dalam peningkatan stabilitas kimia dan freeze-thaw polimer (Peter \& El-Aasser, 1997) dan pengaruh jenis surfaktan beserta konsentrasinya terhadap viskositas akan dipelajari. Adapun nilai kebaruan pada penelitian ini terdapat pada pembandingan penggunaan surfaktan nonionik NP-06 dan NP10 yang belum pernah dilakukan sebelumnya.

\section{METODOLOGI PENELITIAN}

\section{Bahan dan Peralatan}

Proses pembuatan PVAc dari monomer VAM dengan reaksi adisi radikal bebas fase cair dalam reaktor tangki berpengaduk. Reaksi bersifat eksotermis dan irreversible, karenanya dilengkapi dengan koil pendingin untuk menjaga stabilitas suhunya. Ammonium persulfat (APS) digunakan sebagai inisiator dan kondisi operasi yang digunakan adalah tekanan $1 \mathrm{~atm}$, suhu 75 hingga $85^{\circ} \mathrm{C}$. Selain itu bahan baku lain yang digunakan adalah polivinil alkohol (PVOH) dan air suling.

Alat yang digunakan antara lain berupa reaktor, pengukur suhu, penangas air, pengaduk jenis double blade, droping funel dan buret.

\section{Prosedur Penelitian}

Polimerisasi dilakukan dengan pembuatan larutan $\mathrm{PVOH}$ terlebih dahulu di suhu $90^{\circ} \mathrm{C}$ $94^{\circ} \mathrm{C}$ hingga bubuk $\mathrm{PVOH}$ larut sempurna. Setelah itu suhu reaktor diturunkan menjadi suhu operasi polimerisasi di angka $75^{\circ} \mathrm{C}-80^{\circ} \mathrm{C}$. Kelengkapan reaktor antara lain adalah kontrol temperatur, kontrol laju alir pengaduk, droping funel dan buret. Setelah suhu mencapai $80^{\circ} \mathrm{C}$, surfaktan masuk ke dalam reaktor dan dibiarkan 5 menit supaya larut bersama larutan $\mathrm{PVOH}$. Setelah itu proses pembentukan partikel PVAC dapat dimulai dengan memasukkan tetesan monomer VAM dan APS secara bersamaan selama $3-6$ jam hingga habis.Setelah itu, biarkan proses sintesis berjalan dengan tambahan waktu 30 menit hingga 1 jam. Hal ini dimaksudkan untuk mereaksikan partikel-partikel monomer yang belum terkonversi menjadi polimer. Setelah tambahan waktu, suhu reaktor diturunkan ke suhu kamar dan disaring dengan ukuran mesh tertentu supaya kotoran dapat terpisah. Selanjutnya karakterisasi dapat dilakukan pada hari berikutnya.

Karakterisasi dilakukan dengan mengukur viskositas dalam kondisi suhu ruangan $\left(25^{\circ} \mathrm{C}\right)$ 
dengan menggunakan viskometer Brookfield. Viskositas merupakan parameter penting bagi polimer cair seperti PVAc (Chern, 2006). Kemudian hal ini dapat dilakukan lagi dengan variabel sintesis yang lain. Secara umum, gambaran perlengkapan polimerisasi PVAc dapat dilihat pada Gambar 1.

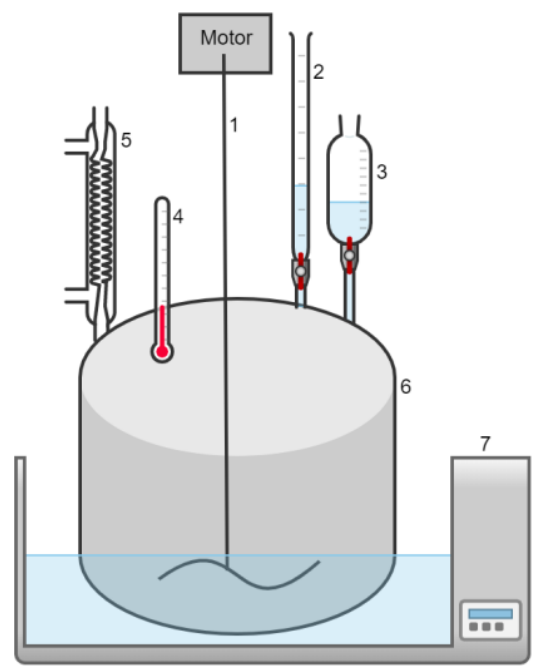

Gambar 1. Polimerisasi PVAc

Keterangan:

1) Pengaduk

2) Buret

3) Droping funel

4) Termometer

5) Kondensor

6) Reaktor

7) Water bath

\section{HASIL DAN PEMBAHASAN}

\section{Pengaruh Surfaktan Non-Ionik NP-06 dan NP-10}

Sintesis polimer PVAc dilakukan dengan pembuatan 3 jenis sampel yang masingmasing diberi label dengan nama sampel $A$ (tanpa surfaktan), sampel B (dengan surfaktan NP-6) dan sampel C (dengan surfaktan NP-10). Hasil pengukuran viskositas ketiga sampel tersebut dapat dilihat pada Gambar 2.

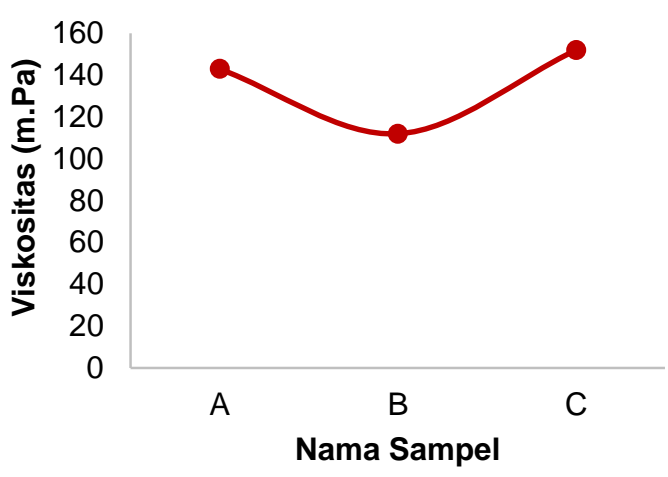

Gambar 2. Viskositas sampel

Terlihat bahwa ada penurunan viskositas setelah penambahan surfaktan NP-06. Hal ini disebabkan karena surfaktan jenis NP memiliki molekul etilen oksida ( $\mathrm{Bu}$ et al., 2019), sedangkan etilen oksida (EO) dapat bereaksi dengan gugus $\mathrm{OH}$ dari air maupun $\mathrm{PVOH}$ untuk membentuk etilen glikol (Dini, 2017) seperti yang diilustrasikan pada Gambar 3 dan Gambar 4. Hal ini mengurangi sifat hidrofobisitas polimer menyebabkan rantai polimer yang terbentuk menjadi lebih pendek.

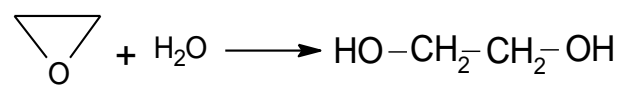

Gambar 3. Reaksi EO dan air<smiles>OCCO[Pb]CCO[C@H]1CO1</smiles>

Gambar 4. Reaksi EO dan senyawa $\mathrm{OH}$

Peningkatan viskositas pada NP-10 terjadi karena kandungan EO pada NP-10 yang lebih banyak daripada NP-06.

\section{Pengaruh Variasi Konsentrasi Surfaktan Non-Ionik NP-06 dan NP-10}

Sintesis PVAc dilakukan dengan membuat variasi konsentrasi surfaktannya. Hasil dari variasi tersebut dapat dilihat pada Gambar 5. 


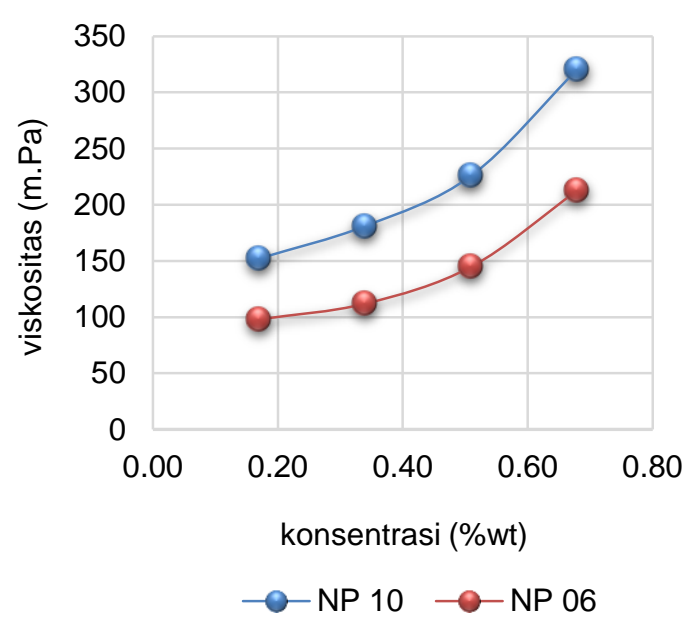

Gambar 5. Pengaruh konsentrasi surfaktan terhadap viskositas PVAc

Dari Gambar 5, didapat bahwa semakin tinggi nilai konsentrasi, viskositas semakin meningkat. Hal ini dikarenakan semakin tinggi konsentrasi surfaktan non-ionik akan meningkatkan jumlah etilen oksida yang akan menyebabkan semakin menurunnya berat molekul (Sihombing \& Ngatin, 2019). Dampaknya akan menghasilkan partikel polimer yang berukuran lebih kecil (Sarac et al., 2002). Sehingga jumlah partikel per satuan unit meningkat dan akhirnya viskositas meningkat.

\section{KESIMPULAN}

Homopolimer PVAc berbasis air telah berhasil disintesis dengan mereaksikan monomer VAM, PVOH, APS dan menggunakan variasi konsensentrasi surfaktan non-ionik sebagai variabel berubahnya. Dibandingkan sampel tanpa surfaktan yang memiliki viskositas $143 \mathrm{~m} . \mathrm{Pa}$, penggunaan surfaktan NP-06 menghasilkan viskositas 98 m.Pa dan surfaktan NP-10 menghasilkan viskositas $152 \mathrm{~m} . P a$. Sedangkan untuk variasi konsentrasi surfaktan NP-06 dari $0.17 \%$ wt hingga $0.68 \%$ wt menghasilkan viskositas 98 $\mathrm{m} . \mathrm{Pa}$ hingga $213 \mathrm{~m} . \mathrm{Pa}$ dan untuk variasi konsentrasi surfaktan NP-10 dari $0.17 \%$ wt hingga $0.68 \%$ wt menghasilkan viskositas di $152 \mathrm{~m}$. Pa hingga $321 \mathrm{~m} . \mathrm{Pa}$.

Dengan penelitian ini, diharapkan fenomena perubahan viskositas dapat dijadikan acuan bagi para pelaku industri perekat, terutama perekat homopolimer PVAc berbasis air.

\section{UCAPAN TERIMA KASIH}

Ucapan terima kasih disampaikan kepada Politeknik Negeri Bandung atas dukungannya dalam memberikan pembiayaan melalui Penelitian Mandiri dengan Surat Perjanjian nomor B/ 249.134/ PL1.R7/ PG.00.03/ 2020.

\section{DAFTAR PUSTAKA}

Berber, H., Tamer, Y., \& Yildirim, H. (2018). The effects of feeding ratio on final properties of vinyl acetate-based latexes via semicontinuous emulsion copolymerization. Colloid and Polymer Science, 296(1): 211-221.

Bu, F., Liu, J., Bai, Y., Kanungo, D. P., Song, Z., Kong, F., \& Pan, C. (2019). Effects of the preparation conditions and reinforcement mechanism of polyvinyl acetate soil stabilizer. Polymers, 11(3): 115.

Chern, C. S. (2006). Emulsion polymerization mechanisms and kinetics. Progress in Polymer Science (Oxford), 31(5): 443486.

Dini, R. I. (2017). Pengaruh penambahan polietilen glikol diakrilat terhadap karakteristik hidrogel film untuk aplikasi pembalut luka. [Skripsi]. Universitas Muhammadiyah Purwokerto, Purwokerto hlm. 5-9.

Hong, W., Meng, M., Xie, J., Gao, D., Xian, M., Wen, S., Huang, S.,Kang, C. (2018). Properties and thermal analysis study of modified polyvinyl acetate (PVA) adhesive. Journal of Adhesion Science and Technology, 32(19): 2180-2194. 
Helmiyati., Budianto, E., Arinda, N,. (2009). Polimerisasi Emulsi Etil Akrilat: Pengaruh Konsentrasi Surfaktan. Inisiator Dan Teknik. 13(1): 59-64.

Kemenperin. (2014). Perkembangan Jumlah Unit Usaha Industri Besar dan Sedang Indonesia.https://kemenperin.go.id/statisti k/ibs indikator.php?indikator $=1$ \&tahun $=2$ 010, diakses 12 Januari 2020

Peter, A. Lovell \& El-Aasser, Mohamed S.. (1997). Emulsion Polymerization and Emulsion Polymers. Wiley, New Jersey.

Sarac, A., Yildirim Erbil, H., \& Yildirim, H. (2002). Semicontinuous emulsion polymerization of vinyl acetate: Effect of ethoxylation degree of nonionic emulsifiers. Journal of Applied Polymer Science, 86(4): 844-851.

Shahidi, F. (2009). Bailey 'S Industrial Oil and Fat Production (Vol. 1). John Wiley \& Sons, Ltd., New Jersey.

Sihombing, R. P., \& Ngatin, A. (2019). Modifikasi Homopolimer Poli (Vinil Asetat) dengan Variabel Hidrofobisitas Emulsifier untuk Aplikasi Perkayuan. Jurnal Fluida, 12(2): 72-77.

Susilowati, B. (2011). Resiko Kesehatan Terhadap Pajanan Benzene Pada Pekerja Industri Sepatu Kulit di PIK Pulogadung Tahun 2011. [Skripsi]. Universitas Indonesia, Depok.

Triwulandari, E. (2014). Studi Poimerisasi Antarmuka Terhadap Distribusi Ukuran Partikel Mikrokapsul Poliuretan Berbasis Gliserol. [Tesis]. FMIPA Universitas Indonesis, Depok.

Wang, Q., Fu, S., \& Yu, T. (1994). Emulsion Polymerization. Prog. Polym. Sci, 19: 703753 